\title{
Translational research in agricultural biology-enhancing crop resistivity against environmental stress alongside nutritional quality
}

\author{
Autar K. Mattoo* \\ Sustainable Agricultural Systems Laboratory, United States Department of Agriculture, The Henry A. Wallace Beltsville Agricultural Research Center, Agricultural \\ Research Service, Beltsville, MD, USA \\ ${ }^{*}$ Correspondence: autar.mattoo@ars.usda.gov
}

Edited and reviewed by:

Angelos K. Kanellis, Aristotle University of Thessaloniki, Greece

Keywords: antioxidants/nutrients, biotechnology, legume cover crops, genetic engineering, metabolomics, smart crops, sustainable agriculture, transcription factors

\begin{abstract}
"Plants Are Smarter Than We Thought" was the headline news recently in a leading journal (Science News, March 6, 2014; http://news.sciencemag.org/signal - noise/ 2014/03/ plants-are-smarter-we-thought), highlighting an article published elsewhere (Meyer et al., 2014), which presented evidence that plants are able to make smart decisions in response to predation and environment. Plants are well known to have evolved a fascinating adaptability to environment likely because of their sessile nature. Among a long list of complex and unique processes that plants have evolved include the oxygen evolving process of photosynthesis (Ort and Yocum, 1996; Demmig-Adams et al., 2006), which is the life force of ani$\mathrm{mal} /$ mammalian kingdoms, carried out by the semi-autonomous organelle, the chloroplast (Wise and Hoober, 2007); totipotency such that any cell from any plant part can divide, differentiate and yield a fully functional plant (Chupeau
\end{abstract} et al., 2013); the ability of and restoring structural (Meyer et al., 2014) and metabolic memory (Mattoo et al., 2007; Mattoo and Handa, 2008); the differentiated chromoplasts (from chloroplasts) that store important nutrients for animal and human health (Egea et al., 2010); long distance signaling up and down the whole plant (Ruiz-Medrano et al., 2001; Köhler and Mueller-Roeber, 2004); and recognition and communication via the emission of select class of volatiles (Holopainen and Blande, 2012; Das et al., 2013). Although the phenomenology is well described, the molecular and biochemical mechanisms involved in these processes are better known of some than other of these complex processes. The application of chemistry (and physics) principles has considerably added to the progress made in our understanding of plant life thus far.

Life on earth became possible some 3.5 billion years ago because "chemistry begat biology" (Aberlin, 2014). However, little is known or understood of what led to the transition from chemistry to biology (Quoted from Jack Szostak, Harvard Medical School, February 2012, as appeared in The Scientist 03-2014). Nonetheless, the past two centuries witnessed a close merger between chemistry (and physics) and biology, producing a distinct platform for biochemistry (Neuberg, 1903 in en.wikipedia.org/wiki/Carl_Neuberg1) to bear on our understanding of the functions of a living cell and its complex nature. Because of its very nature, this discipline unearthed common and distinct alphabets and trends of biochemical processes that led to a concept of "unity in diversity," exemplifying common principles that underlie the uniformity of life in diverse kingdoms. Kluyver's studies on microorganisms led to the discovery that ecological microbiology has a biochemical basis (Kluyver, 1924 in Florkin, 1960). The discovery that all the diverse organisms harbor same macromolecules and genetic code led to the knowledge that all organisms, from microorganisms to human beings, are built from similar molecular components with some variations (Berg et al., 2002).

The past century was a witness to advances in diverse disciplines including genetics, and micro- and macro-elements of biological chemistry. Thus, major discoveries were made on biochemical pathways (by Krebs, encompassing 1932, 1937, and 1957), cofactors (for instance, coenzyme A, by Fritz A. Lippman), enzymes (by Wilhelm Kuhne, as early as 1878), proteins (by Sumner), nucleic acids-DNA (by Watson and Crick) and RNA world (http://en.wikipedia.org/wiki/History_of_ RNA_biology), cell membrane function and signaling pathways (http://en.wikipedia.org/wiki/History_of_ biochemistry). These advances and discoveries brought together pieces of the puzzle(s) and laid the foundation for modern day molecular biology, biotechnology and epigenetic regulation. Progress in the identification and quantification of low abundant molecules led to Metabolome, which delves into the plasticity and/or homeostasis of primary and secondary metabolites, while small RNAs (including snoRNAs and miRNAs) brought to the fore the regulation by non-coding RNAs. Now and again, chemistry is having a bearing on the tremendous progress made in life sciences and our understanding of the biological processes.

The application of the innovative recombinant DNA technology enabled transfer of genes across kingdoms, creating the modern day biotechnological intervention to revolutionize research, and changing for good the paradigms in 
agricultural and medical research (Cohen et al., 1973). Transgenic research is the buzzword for all sorts of remedial measures, be that to prevent/solve diseases, produce recombinant products, or grow more food. Because of the totipotency of the plant cells, plant biologists were able to transform and develop plants engineered with novel, heterologous and endogenous genes. This has enabled unambiguous confirmation of gene function in planta and testing the novel genotypes for global changes in macromolecules and micromolecules alike. The detection, unambiguous identification, quantification and fast analysis of minutest amounts of cellular micromolecules including plant hormones has materialized through high resolution superior gas chromatography, ultra high performance liquid chromatography coupled to triple-quadrupole mass spectrometer, and Nuclear Magnetic Resonance (NMR) Spectroscopy, and this has become instrumental in understanding the chemical footprints during different phases of growth and development of plants.

The human genome sequencing was completed ahead of expected time, and this success catalyzed moves to sequence other genomes including crop plants, all expedited by the progress made in Information Technology - mining the data and putting pieces of the puzzle together in shortest time possible. Progress in the Genomics (http://www. sciencemag.org/site/feature/misc/webfeat/ plantgenomes/feature.html) field ushered in the Epigenomics (Schmitz and Zhang, 2011) science, and together they have thrown the whole biological kingdom wide open to new research, furthering our understanding of the fundamental basis of life, development and regulation. The length and breadth of data that accumulate each day is humongous and has led to the active collaboration in the interface of bioinformatics and biology. This merging of two disciplines has enhanced the timely solutions and brought to bear on the way science in this century is being conducted worldwide.

More importantly, these advances in technology and biology have prepared the groundwork for the benefit of the humankind by providing reagents and roadmaps to solve the issues world is faced with at this time. This is most applicable and needed for human welfare, to have agricultural sustainability and feed the world, because there clearly is an increasing population growth trend throughout the globe except in Europe. World human population is expected to reach close to 9.6 billion by 2050 (http://esa.un.org/wpp/). The production capacity to grow more food to meet the demands of the burgeoning population gets complicated in view of the limits in the arable land that is less and less available, declining trends in crop yields, less sustainability of resources such as water, and losses due to abiotic and biotic stresses. Added to the challenge in producing more (nutritious) food is the need to fight malnutrition and reduce extensive chemical use in agriculture for a cleaner environment. Breeding strategies employing markerassisted selection for high yielding varieties as well as for identifying germplasm resistant to abiotic and biotic stresses are already in vogue. Another approach is to introduce agronomically important genes and those that can help crops withstand environmental extremes into major and minor crops using genetic engineering technology.

\section{MAKING BIOTECHNOLOGY MORE SUSTAINABLE}

Biological revolution-genetic engineering and biotechnology-has a promise to enhance crop resilience and make a breeder's dream come true: produce more in a shorter time, reduce our reliance on agricultural chemicals such as pesticides and fungicides, and add to environmentfriendly sustainable agriculture (Mattoo, 2013). Some of the desirable traits that have been successfully introduced into crops by genetic engineering include insect resistance, disease resistance, herbicide tolerance, chilling tolerance, delayed fruit ripening, prolonged shelf-life, texture and processing attributes. Irrespective of this promise, the rapid pace in the development of novel engineered crops and the considerable interest generated among growers and consumers, the application of this technology and/or acceptance of genetically engineered foods world-wide has been hampered by continued debate on the safety of such produce. These issues include ethical concerns, potential toxicity, selection markers, undesired gene flow, development of resistance against herbicides and pesticides. Significant research efforts have gone into satisfying the consumers' concerns. Risk assessment studies have focused on determining the substantial equivalence of genetically engineered food and traditionally-bred wild type crops. In such studies, optimized unambiguous methodologies are required to search for differences between the engineered and non-engineered food. Many studies in the literature have not revealed any unusual compound in the genetically engineered crops, suggesting that they are basically substantially equivalent to non-engineered foods (Baker et al., 2006; Mattoo et al., 2006; Sobolev et al., 2010; Farre et al., 2011).

Plant-breeding programs normally include assessing and accounting the influence of genetic background $(G)$, ecosystem environment $(\mathrm{E})$, and $\mathrm{G} \times \mathrm{E}$ interactions singly and/or together on their impact on the growth and development of crops/plants, particularly for producing suitable genotypes for multiple environments (El-Soda et al., 2014). Evaluating these parameters also helps understand plant fitness trade-offs and evolutionary ecology El-Soda et al. (2014). Because the genetically engineered plants harbor a modified gene(s) and the positioning of the introduced gene is mostly a random event, it seems important that such plants be tested for agronomic and biological performance in the fields under multiple ecosystem services to assess which production system is conducive for impact on different parameters of the engineered plant(s) grown side by side the nonengineered wild type control(s). Studies of this kind/nature reported in the literature are miniscule.

It is imperative that controlled field studies of genetically engineered and other crops are carried out in an unambiguous manner alongside the wild type to ascertain which production system may provide the best medium. Such studies are expected to provide new ways to leverage growth enhancement, crop resistance to stresses, and improve the nutrient content of the edible produce in an eco-friendly environment. For instance, a major agriculturally utilized genetic event is the 
introduction of the Bacillus thuringenesis (Bt) protein gene in diverse crops, particularly cotton and maize, to make these crops resistant to insect pests (Marvier et al., 2007; James, 2013). The Bt crops have generated good revenue both for the farmer and the industry. However, like the nonengineered crops that suffer losses because of the adaptability of insects and microbial pathogens, it is expected that Bt crops and other such novel genetic materials will also be manipulated by the pathogens in the long run. Thus, in the field evaluation, populations of western rootworm were identified that had developed resistance to multiple Bt-maize toxins (Gassmann et al., 2014). In the above-mentioned context, i.e., developing a friendlier ecosystem suitable for growing each crop with a unique genetic event(s), it is of critical importance to understand their long-term performance in practical terms as well as a novel resource to discern various players in biological adaptability. Thus, studies that were geared to test the effect of natural predators in a defined ecosystem on the performance of Bt crops demonstrated that, indeed, natural enemies of insects help delay the development of insect resistance to Bt crops (Liu et al., 2014). Just as in conventional breeding strategies, so with novel biotech crops any unusual observation(s) in field performance behavior will have to be scientifically tackled and rectified.

\section{DEVELOPING ROBUST CROP PLANTS TO RESIST ABIOTIC STRESSORS}

Plant growth in nature is compromised on a daily basis because plants expend energy to adjust and adapt to changing environment, which becomes more precarious under additional stresses due to drought and extreme temperatures, for instance, excessive summer temperatures of the tropics, or in cooler climatic situations. Thus, water availability, temperature, soil properties and ecosystem can dictate the growth response and yield of a crop plant. Moreover, each plant adapts to environment based on the genetic make up, accordingly impacting growth, development and yield (Porter and Semenov, 2005).

Molecular responses to unfavorable environment include a medley of genes and signal transduction pathways that are tightly regulated and empower plants to combat the stress conditions. Although much of this regulation is at transcriptional, post-transcriptional, and post-translational levels, the intricacy is of essence at the transcriptional level involving chromatin modification and remodeling, cis-regulatory elements located upstream and downstream the coding region of the gene, and trans regulatory transcription factors (Luo et al., 2012). Also, other important players that are directly or indirectly associated with imparting tolerance to abiotic stresses include protective proteins (including dehydrins, heat shock proteins-HSPs, Late Embryogenesis Abundant proteinsLEA Vierling, 1991; Wang et al., 2004; Kazuko and Shinozaki, 2006; Lipiec et al., 2013; Mu et al., 2013), osmolytes (proline/trehalose/sugars Fougere et al., 1991; Petrusa and Winicov, 1997; Wingler, 2002; Avonce et al., 2006; Ito et al., 2006; Ge et al., 2008; Zhang et al., 2010; Hayat et al., 2012; Yanhui et al., 2012), glycine betaine (Sakamoto and Murata, 2002; Quan et al., 2004; Wang et al., 2010; Chen and Murata, 2011), signaling molecules (polyamines Roy and Wu, 2002; Navakouidis et al., 2003; Capell et al., 2004; Kasukabe et al., 2006; Alcázar et al., 2010; Wi et al., 2006; Liu et al., 2007; Kusano et al., 2008; Wen et al., 2008; Cheng et al., 2009; Kalamaki et al., 2009; Gill and Tuteja, 2010; Shukla and Mattoo, 2010; inositol Xiong et al., 2001; Sengupta et al., 2008); and hormones (abscisic acidABA Davies and Zhang, 1991; Saradhi et al., 2000; ethylene- $-\mathrm{C}_{2} \mathrm{H}_{4}$ Hinz et al., 2010; Quan et al., 2010; Xiong et al., 2013; and methyl jasmonate-meJA Bartels and Sunkar, 2005; Vincour and Altman, 2005; Wu et al., 2008; Jan et al., 2013), several of which have been validated for mitigating abiotic stresses.

Genome sequencing of model and crop plants before and after exposure to a given stress has identified candidate genes whose role(s) in response to different abiotic stresses can then be tested/validated by expression and down-regulation in homologous as well as in heterologous systems. Thus, stress responsive genes including specific transcription factors have been identified by comparative transcriptomics. Enormous activity regarding validated data on a few crops for the involvement of transcription factors (b-ZIP,
ERF/AP2 family, DOF, HD-ZIP, MYB, NAC, WRKY, and Zn-finger) (Riechmann and Ratcliffe, 2000; Dubouzet et al., 2003; $\mathrm{Hu}$ et al., 2006; Ito et al., 2006; Mittler, 2006; Nakashima et al., 2007; Weiste et al., 2007; Wu et al., 2008; Xiang et al., 2008; Zou et al., 2008; Gao et al., 2009; Lu et al., 2009; Oh et al., 2009; Jeong et al., 2010; Su et al., 2010; Takasaki et al., 2010; Zhang et al., 2010; Zhao et al., 2010; Wan et al., 2011; Liu et al., 2012; Yang et al., 2012; Jan et al., 2013), and other genes (CDPKs, HAP/CAAT, HSPs-LEA family, MAPKKK) (Vierling, 1991; Saijo et al., 2000; Wang et al., 2004; Chandra Babu et al., 2004; Shou et al., 2004; Kazuko and Shinozaki, 2006; Xu et al., 1996; Nelson et al., 2007; Xiao et al., 2007; Ning et al., 2010; Duan and Cai, 2012; Lipiec et al., 2013; Mu et al., 2013) have shown the true promise of these candidates as stress modulators. Members from each transcription factor family show protective phenotypes against multiple stresses such as cold, drought and excess salt (summarized in Figure 1; Shukla and Mattoo, 2013; Mattoo et al., 2014). Similarly, engineering targeted metabolic pathways enable multi-throng efforts to produce and sustain agricultural commodities for the benefit of the farmer and the consumer (Reugera et al., 2012).

Such successful efforts on engineering crop plants for resistance to different abiotic stresses have started paying dividends since industry has generated some drought resistant germplasm for the farmers. This progress in translating basic research into viable products offers a roadmap for intensifying efforts to develop resistant germplasm for all the major and minor crops and test them under varied climatic conditions and different ecosystems worldwide.

\section{NUTRIENT-ENHANCED PRODUCE AND HUMAN HEALTH}

It is more and more recognized that phytonutrient-rich diet containing high dose of antioxidants/vitamins, present in fruit and vegetables, potentially prevents polygenic diseases such as epithelial cancers, diabetes, atherosclerosis, hypertension, cardiovascular diseases and osteoporosis (Mattoo et al., 2010; Shukla and Mattoo, 2010; Fatima et al., 2013). This is the reason that antioxidant/vitamin supplements are available over the counter 


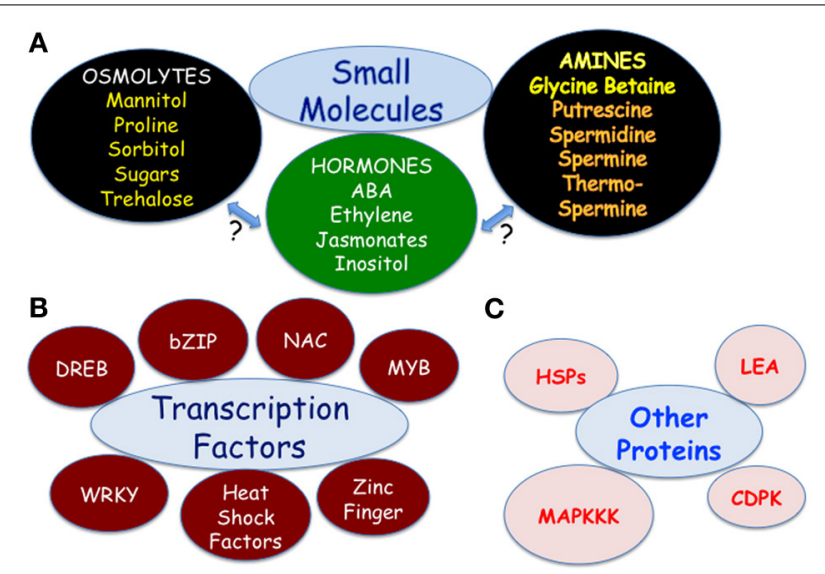

FIGURE 1 | Players that empower crop plants to withstand abiotic stresses-drought, temperature extremes and high saline soils. (A) Small molecules such as osmolytes, biogenic amines and hormones. (B) Transcriptional factors. (C) Heat shock proteins (chaperone proteins) and protein kinases.

in pharmacies and grocery stores worldwide. The well-known health-promoting phytonutrients that have been proposed to alleviate disease symptoms and reduce incidence of diseases include carotenoids ( $\beta$-carotene, lutein, lycopene), polyphenolics/flavonoids, vitamins $\mathrm{C}$ and $\mathrm{E}$, isothiocyanates and glucosinolates. That disease and nutrition are intertwined in humans is becoming relevant in this science/technology, post-genomic era and the beneficial effects seem linked to interactions among different antioxidants present in food, although little is known about the nature of these interactions (Shukla and Mattoo, 2010; Fatima et al., 2013). Thus, the need for a dense nutrient intake through eating a variety of foods including grains, fruits and vegetables has been emphasized in the dietary guidelines for Americans (http://www. dietaryguidelines.gov).

The increasing interest in the bioactive molecules present in grains, fruits and vegetables has catalyzed research interest in developing definitive basic information on their content, with more than 40 such molecules having been identified and deemed essential for a healthy life (Failla, 2012). The quantity required of each nutrient to decrease "disease risk" is a critical factor while bioavailability of nutrients in a diet determines how much of the good nutrient's potential is realized (Shukla and Mattoo, 2010; Fatima et al., 2013). Although grains, vegetables, and fruits are sources of antioxidants and vitamin nutrients, the levels in general are low, likely due to tight genetic and developmental controls of their metabolic pathways during plant growth and development (Paine et al., 2005). Further, biosynthetic pathways for phytonutrients and their regulation are incomplete in many instances, and "germplasm" with higher accumulation of phytonutrients is not easily available. Modern tools of metabolomics have already overcome these limitations by identifying, purifying and quantifying hundreds of biochemicals (Mattoo et al., 2006; Saito and Matsuda, 2010). Mutagenesis and TILLING (Targeting Induced Local Lesions in Genomes) approaches are being used to use selection against genes that negatively regulate biosynthesis or accumulation of phytonutrients (Zhang et al., 2009; Handa et al., 2011).

Molecular genetics is now providing tools to identify and characterize genes regulating the biosynthesis of phytonutrients in plants. Thus, genetic/metabolic engineering of the rate limiting steps in the biosynthesis of a compound has facilitated increased levels of phytonutrients in plant tissues/organs (Shukla and Mattoo, 2010; Fitzpatrick et al., 2012; Fatima et al., 2013; Handa et al., 2014). Animal and human trials can help determine which nutrient(s) needs to be enhanced through molecular strategies designed to increase their contents in grains, vegetables, and fruits. Interestingly, the human health paradigm has been revised to include preventive, dietary intervention to ameliorate diseases and physiological disorders. More scientific research and validation are required before phytonutrients become a "mantra" for healthy living (Handa et al., 2014).

Regulatable promoters fused to heterologous genes allowed higher levels of carotenoids to accumulate in a fruitspecific manner in tomato (Rosati et al., 2000; Dharmapuri et al., 2002; Fraser et al., 2002; Mehta et al., 2002), and similarly in other instances where constitutive promoters were employed (Römer et al., 2000; D'Ambrosio et al., 2004). Use of regulatable promoters fused to the E. coli DXS gene (Enfissi et al., 2005) or suppression RNAi to downregulate the photomorphogenesis regulatory protein gene DET1 (Davuluri et al., 2005) also led to high levels of carotenoids in tomato fruit. Also, metabolic engineering of polyamine biosynthesis in tomato by introducing fruit-specific expression of yeast S-adenosylmethionine (SAM) decarboxylase gene led to $200-300 \%$ increase in lycopene content (Mehta et al., 2002) while constitutive expression of yeast spermidine synthase increased carotenoid content by $40 \%$ (Nambessan et al., 2010). TOMATO AGAMOUS-LIKE 1 (TAGL1), a $M A D S$-box transcription factor, expression resulted in higher accumulation of lycopene and naringenin chalcone (Itkin et al., 2009). Another study used RNAi-mediated fruit-specific suppression of 9-cis-epoxycarotenoid dioxygenase 3 (NCED3) to suppress ABA synthesis to stimulate accumulation of upstream compounds such as $\beta$-carotene and lycopene in transgenic tomato fruits (Sun et al., 2012). In this regard, a mutation in zep 1 caused ABA-deficiency in tomato plants with concomitant accumulation of $30 \%$ more carotenoids in mature red tomato fruit (Galpaz et al., 2008).

A few other selective examples of engineering phytonutrient content are:

GDP-L-galactose phosphorylase (VTC2) expression increased vitamin $\mathrm{C}$ level in tomato, strawberry, and potato by 2-6 fold (Bulley et al., 2012); mammalian GTP cyclohydrolase I caused 140 -fold increase in pteridine and 2fold increase in folate, and by combining with aminodeoxychorismate synthase (PABA biosynthesis), folate levels were 
increased 19-fold (Diaz de la Garza et al., 2007); expression of $\alpha$-tocopherol methyltransferase and $\gamma$-tocopherol methyltransferase, respectively in soy oil and lettuce, increased vitamin E severalfold (see Fatima et al., 2013); simultaneous expression of genes for $\beta$-carotene, ascorbate, and folate biosynthetic pathways increased $\beta$-carotene (169-fold), ascorbate (6-fold), and folate (2-fold) in corn (Naqvi et al., 2009); expression of Roseal and Delila or flavonoid-related R2R3-MYB increased flavonoid content in tomato pericarp (Butelli et al., 2008); RNAi suppression of the DE-ETIOLATED1 (DET1) gene (a photomorphogenesis regulatory gene) caused several-fold increase in carotenoid, tocopherol, phenylpropanoids and flavonoids (Enfissi et al., 2010); metabolic engineering of diverse genes that encode enzymes for secondary metabolites all increased content of polyphenolic flavonoids in tomato fruit (Muir et al., 2001; Niggeweg et al., 2004; Giliberto et al., 2005; Schijlen et al., 2006), $\alpha$-tocopherol (vitamin E) in potato tubers (Crowell et al., 2008), and some produced novel flavonoids in tomato fruit (Schijlen et al., 2006).

It is apparent that modern biotechnology in conjunction with Metabolomics is enabling tissue specific redesign of primary and secondary metabolic pathways so as to accumulate high levels of phytonutrients in different plant systems. Thus, transgenic crops are an addition to the genetic resource to further define genetic, biochemical, and physiological regulation of cellular metabolism pathways, including enhancing functional metabolites in produce and provide novel "specialty crops" to the public. In return, public awareness of benefits of consumer-driven products such as in human health will further add to new markets for specialty, highly nutritious crops.

\section{FUTURE PERSPECTIVE}

Agricultural biologists have their work cut out for translating large database of fundamental nature from laboratory, growth chamber and greenhouses studies to the field for securing and producing (nutritious) food and making agriculture sustainable. All kinds of transgenic lines have been developed, including transgenic lines that have promise of withstanding environmental extremes (abiotic and biotic) and others that have a high dose of phytonutrients. How they fare in the field is the need of the day, effectiveness of this translation will require diligence and a thorough knowledge of the investigated trait in each crop (Ronald, 2011; Nelissen et al., 2014). Moreover, there appears to be a probability that ecological surprises could be more prevalent because of global climate change and interacting environment extremes (Lindenmayer et al., 2010). Also, the point to note is that nutrient levels in crops are influenced by genotype/cultivar, growth condition and developmental stage of the crop (Shukla and Mattoo, 2010; Lee and Scagel, 2014), therefore unambiguous analysis of edible crops grown under similar conditions in the field is needed to determine the robustness of a trait (Neelam et al., 2008; Mattoo and Teasdale, 2010). Convergence of agriculture with health and wealth is a distinct possibility (Dube et al., 2012), and would also be benefited by developing necessary toolkits to establish bon a fide natural products chemistry and translate it into alternative medicine.

Thus, with the available genetic toolkits together with advanced technologies, chemical genetics, and progression with alternative agricultural practices, future action plan is more or less laid out and roadmap defined for scientists and farmers to work together to meet the challenges the humankind faces in this new century. It is evident that there is a need to prioritize translational research as an important component of bench scientists' goals of research. Certainly, there is hope in the horizon for developing new types of crop plants that can yield more and be nutritious with less inputs, are resilient to harsher environment, and are disease tolerant.

\section{ACKNOWLEDGMENTS}

I wish to thank Dr. Marie Soulière of Frontiers for her comments and suggestions for improving the original manuscript. Mention of trade names or commercial products in this publication is solely for the purpose of providing specific information and does not imply recommendation or endorsement by the U.S. Department of Agriculture.

\section{REFERENCES}

Aberlin, M. B. (2014). Let there be life. The Scientist 13 .

Alcázar, R., Altabella, T., Marco, F., Bortolotti, C., Reymond, M., Koncz, C., et al. (2010). Polyamines: molecules with regulatory functions in plant abiotic stress tolerance. Planta 231, 1237-1249. doi: 10.1007/s00425-010-1130-0

Avonce, N., Mendoza-Vargas, A., Morett, E., and Iturriaga, G. (2006). Insights on the evolution of trehalose biosynthesis. BMC Evol. Biol. 6:109. doi: 10.1186/1471-2148-6-109

Baker, J. M., Hawkins, N. D., Ward, J. L., Lovegrove, A., Napier, J. A., Shewry, P. R., and Beale, M H. (2006). A metabolomic study of substantial equivalence of field-grown genetically modified wheat. Plant Biotechnol. J. 4, 381-392. doi: 10.1111/j.1467-7652.2006.00197.x

Bartels, D., and Sunkar, R. (2005). Drought and salt tolerance in plants. Crit. Rev. Plant Sci. 24, 23-58. doi: 10.1080/07352680590910410

Berg, J. M., Tymoczko, J. L., and Stryer, L. (2002). Biochemistry, 5th Edn. New York, NY: W. H Freeman.

Bulley, S., Wright, M., Rommens, C., Yan, H., Rassam, M., Lin-Wang, K., et al. (2012). Enhancing ascorbate in fruits and tubers through over-expression of the l-galactose pathway gene GDP-l-galactose phosphorylase. Plant Biotechnol. J. 10, 390-397. doi: 10.1111/j.1467-7652.2011.00668.x

Butelli, E., Titta, L., Giorgio, M., Mock, H. P., Matros, A., Peterek, S., et al. (2008). Enrichment of tomato fruit with health-promoting anthocyanins by expression of select transcription factors. Nat. Biotechnol. 26, 1301-1308. doi: 10.1038/nbt.1506

Capell, T., Bassie, L., and Christou, P. (2004). Modulation of the polyamine biosynthetic pathway in transgenic rice confers tolerance to drought stress. Proc. Natl. Acad. Sci. U.S.A. 101, 990-991. doi: 10.1073/pnas.0306974101

Chandra Babu, R., Zhang, J., Blum, A., Hod, T. H. D., Wue, R., and Nguyen, H. T. (2004). HVA1, a LEA gene from barley confers dehydration tolerance in transgenic rice (Oryza sativa L.) via cell membrane protection. Plant Sci. 166, 855-862. doi: 10.1016/j.plantsci.2003.11.023

Chen, T. H., and Murata, N. (2011). Glycinebetaine protects plants against abiotic stress: mechanisms and biotechnological applications. Plant Cell Environ. 34, 1-20. doi: 10.1111/j.13653040.2010.02232.x

Cheng, L., Zou, Y. J., Ding, S. L., Zhang, J. J., Yu, X. L., Cao, J. S., et al. (2009). Polyamine accumulation in transgenic tomato enhances the tolerance to high temperature stress. J. Integr. Plant Biol. 51, 489-499. doi: 10.1111/j.1744-7909.2009.00816.x

Chupeau, M.-C., Granier, F., Pichon, O., Renou, J.-P., Gaudin, V., and Chupeau, Y. (2013). Characterization of the early events leading to totipotency in an Arabidopsis protoplast liquid culture by temporal transcript profiling. Plant Cell 25, 2444-2463. doi: 10.1105/tpc.113.109538

Cohen, S., Chang, A., Boyer, H., and Helling, R. (1973). Construction of biologically functional bacterial plasmids in vitro. Proc. Natl. Acad. Sci. U.S.A. 70, 3240-3244. doi: 10.1073/pnas.70.11.3240

Crowell, E. F., McGrath, J. M., and Douches, D. S. (2008). Accumulation of vitamin E in potato 
(Solanum tuberosum) tubers. Transgenic Res. 17, 205-217. doi: 10.1007/s11248-007-9091-1

D’Ambrosio, G., Griorio, G., Marino, I., Merendino, A., Petrozza, A., Salfi, L., et al. (2004). Virtually complete conversion of lycopene into $\beta$-carotene in fruits of tomato plants transformed with the tomato lycopene $\beta$-cyclase (tlcy-b) cDNA. Plant Sci. 166, 207-214. doi: 10.1016/j.plantsci.2003.09.015

Das, A., Lee, S.-H., Hyun, T. K., Kim, S.-W., and Kim, J.-Y. (2013). Plant volatiles as method of communication. Plant Biotechnol. Rep. 7, 9-26. doi: 10.1007/s11816-012-0236-1

Davies, W. J., and Zhang, J. (1991). Root signals and the regulation of growth and development of plants in drying soil. Annu. Rev. Plant Physiol. 42, 55-76. doi: 10.1146/annurev.pp.42.060191. 000415

Davuluri, G. R., van Tuinen, A., Fraser, P. D., Manfredonia, A., Newman, R., Burgess, D., et al. (2005). Fruit-specific RNAi-mediated suppression of DET1 enhances tomato nutritional quality. Nat. Biotechnol. 7, 825-826. doi: 10.1038/nbt1108

Demmig-Adams, B., Adams, W. W. 3rd, and Mattoo, A. K. (eds.). (2006). Photoprotection, Photoinhibition, Gene Regulation, and Environment. Advances in Photosynthesis and Respiration, Vol. 21. Dordrecht: Springer.

Dharmapuri, S., Rosati, C., Pallara, P., Aquilani, R., Bouvier, F., Camara, B., et al. (2002). Metabolic engineering of xanthophyll content in tomato fruits. FEBS Lett. 519, 30-34. doi: 10.1016/S00145793(02)02699-6

Diaz de la Garza, R. I., Gregory, J. F. 3rd, and Hanson, A. D. (2007). Folate biofortification of tomato fruit. Proc. Natl. Acad. Sci. U.S.A. 104, 4218-4222. doi: 10.1073/pnas.0700409104

Duan, J., and Cai, W. (2012). OsLEA3-2, an abiotic sress induced gene of rice plays a key role in salt and drought tolerance. PLOS ONE 7:e45117. doi: 10.1371/journal.pone.0045117

Dube, L., Pingali, P., and Webb, P. (2012). Paths of convergence for agriculture, health, and wealth. Proc. Natl. Acad. Sci. U.S.A. 109, 12294-12301. doi: 10.1073/pnas.0912951109

Dubouzet, J. G., Sakuma, Y., Ito, Y., Kasuga, M., Dubouzet, E. G., Miura, S., et al. (2003). OsDREB genes in rice, Oryza sativa L., encode transcription activators that function in drought, high salt and cold responsive gene expression. Plant J. 33, 751-763. doi: 10.1046/j.1365-313X.2003.01661.x

Egea, I., Barson, C., Bian, W., Purgatto, E., Latche, A., Chervin, C., et al. (2010). Chromoplast differentiation: current status and perspectives. Plant Cell Physiol. 51, 1601-1611. doi: 10.1093/pcp/ pcq136

El-Soda, M., Malosetti, M., Zwaan, B. J., Koornneef, M., and Aarts, M. G. M. (2014). Genotype $x$ environment interaction QTL mapping in plants: lessons from Arabidopsis. Trends Plant Sci. doi: 10.1016/j.tplants.2014.01.001. [Epub ahead of print].

Enfissi, E. M. A., Fraser, P. D., Lois, L. M., Boronat, A., Schuch, W., and Bramley, P. M. (2005). Metabolic engineering of the mevalonate and non-mevalonate isopentenyl diphosphate-forming pathways for the production of health-promoting isoprenoids. Plant Biotechnol. J. 2, 17-27. doi: 10.1111/j.1467-7652.2004.00091.x
Enfissi, E. M., Barneche, F., Ahmed, I., Lichtle, C., Gerrish, C., McQuinn, R. P., et al. (2010). Integrative transcript and metabolite analysis of nutritionally enhanced DE-ETIOLATED1 downregulated tomato fruit. Plant Cell 22, 1190-1215. doi: $10.1105 /$ tpc. 110.073866

Failla, M. (2012). "Interdisciplinary team-work for providing global citizens with a safe, adequate and healthy diet," Proceedings 7th International Postharvest Symposium (Malaysia), 6.

Farre, G., Twyman, R., Zhu, C., Capell, T., and Christou, P. (2011). Nutritionally enhanced crops and food security: scientific achievements versus political expediency. Curr. Opin. Biotechnol. 22, 245-251. doi: 10.1016/j.copbio.2010.11.002

Fatima, T., Handa, A. K., and Mattoo, A. K. (2013). "Functional foods: genetics, metabolome, and engineering phytonutrient levels," in Natural Products, Part V, eds K. G. Ramawat and J. -M. Merillon (Berlin; Heidelberg: Springer-Verlag), 1715-1749.

Fitzpatrick, T. B., Basset, G. J., Borel, P., Carrari, F., DellaPenna, D., Fraser, P. D., et al. (2012). Vitamin deficiencies in humans: can plant science help? Plant Cell 24, 395-414. doi: 10.1105/tpc.111.093120

Florkin, M. (1960). Unity and diversity in biochemistry. Pergamon. (Kluyver, A. J. (1924). Eenheid en verscheidenheid in de stofwisseling der microben'. Cbemiscb Week- blud, 21, 266. Unity and diversity in the metabolism of microorganisms.1924 ALbert J. Kluyver Translation from Albert Jan Kluyver, His Life and Work, 1959, North- Holland Publishing Company, Amsterdam).

Fougere, F., Le-Rudulier, D., and Streeter, J. G. (1991). Effects of salt stress on amino acid, organic acid, and carbohydrate composition of roots, bacteroids, and cytosol of alfalfa (Medicago sativa L.). Plant Physiol. 96, 1228-1236. doi: 10.1104/pp.96.4.1228

Fraser, P. D., Romer, S., Shipton, C. A., Mills, P. B., Kiano, J. W., Misawa, N., et al. (2002). Evaluation of transgenic tomato plants expressing an additional phytoene synthase in a fruit-specific manner. Proc. Natl. Acad. Sci. U.S.A. 99, 1092-1097. doi: $10.1073 /$ pnas. 241374598

Galpaz, N., Wang, Q., Menda, N., Zamir, D., and Hirschberg, J. (2008). Abscisic acid deficiency in the tomato mutant high-pigment 3 leading to increased plastid number and higher fruit lycopene content. Plant J. 53, 717-730. doi: 10.1111/j.1365313X.2007.03362.X

Gao, S. Q., Chen, M., Xia, L.-Q., Xiu, H. J., Xu, Z. S., Li, L.-C., et al. (2009). A cotton (Gossypium hirusutum) DRE-binding transcription factor gene, GhDREB, confers enhanced tolerance to drought, high salt, and freezing stresses in transgenic wheat. Plant Cell Rep. 28, 301-311. doi: 10.1007/s00299-008-0623-9

Gassmann, A. J., Petzold-Maxwell, J. L., Clifton, E. H., Dunbar, M. W., Hoffmann, A. M., Ingber, D. A., et al. (2014). Field-evolved resistance by western corn rootworm to multiple Bacillus thuringiensis toxins in transgenic maize. Proc. Natl. Acad. Sci. U.S.A. 111, 5141-5146. doi: 10.1073/pnas.1317179111

Ge, L. F., Chao, D. Y., Shi, M., Zhu, M. Z., Gao, J. P., and Lin, H. X. (2008). Overexpression of the trehlose-6-phosphate phosphatase gene OsTPP1 confers stress tolerance in rice and results in the activation of stress responsive genes. Planta 228, 191-201. doi: 10.1007/s00425-008-0729-x

Giliberto, L., Perrotta, G., Pallara, P., Weller, J. L., Fraser, P. D., Bramley, P. M., et al. (2005). Manipulation of the blue light photoreceptor cryptochrome 2 in tomato affects vegetative development, flowering time, and fruit antioxidant content. Plant Physiol. 137, 199-208. doi: 10.1104/pp.104.051987

Gill, S. S., and Tuteja, N. (2010). Polyamines and abiotic stress tolerance in plants. Plant Signal. Behav. 5, 26-33. doi: 10.4161/psb.5.1.10291

Handa, A. K., Anwar, R., and Mattoo, A. K. (2014). "Biotechnology of fruit quality," in Fruit Ripening: Physiology, Signalling and Genomics, eds P. Nath, M. Bouzayen, A. K. Mattoo, and J.-C. Pech (Oxfordshire, UK: CAB International Publishers).

Handa, A. K., Tiznado-Hernández, M. E., and Mattoo, A. K. (2011). "Fruit development and ripening: a molecular perspective," in Plant Biotechnology and Agriculture: Prospects for the 21st Century, eds A. Altman and P. M. Hasegawa (New York, NY: Oxford Academic Press), 405-424.

Hayat, S., Hayat, Q., Alyemeni. M. N., Wani, A. S., Pichtel, J., and Ahmad, A. (2012). Role of proline under changing environments: a review. Plant Signal. Behav. 1456-1466. doi: 10.4161/psb.21949

Hinz, M., Wilson, I. W., Yang, J., Buerstenbinder, K., Llewellyn, D., Dennis, E. S., et al. (2010). Arabidopsis RAP2.2: an ethylene response transcription factor that is important for hypoxia survival. Plant Physiol. 153, 757-772. doi: 10.1104/pp.110.155077

Holopainen, J. K., and Blande, J. D. (2012). Molecular plant volatile communication. Adv. Exp. Med. Biol. 739, 17-31. doi: 10.1007/978-1-4614-1704-0_2

Hu, H., Dai, M., Yao, J., Xiao, B., Zhang, Q., and Xiong, L. (2006). Overexpressing a NAM, ATAF, and $C U C(N A C)$ transcription factor enhances drought resistance and salt tolerance in rice. Proc. Natl. Acad. Sci. U.S.A. 103, 12987-12992. doi: 10.1073/pnas.0604882103

Itkin, M., Seybold, H., Breitel, D., Rogachev, I., Meir, S., and Aharoni, A. (2009). The TOMATO AGAMOUS-LIKE 1 is a component of the fruit ripening regulatory network. Plant J. 60, 1081-1095. doi: 10.1111/j.1365-313X.2009.04064.x

Ito, Y., Maruyama, K., Taji, T., Kobayashi, M., Seki, M., Shinozaki, K., et al. (2006). Functional analysis of rice $D R E B 1 / C B F$-type transcription factors involved in cold-responsive gene expression in transgenic rice. Plant Cell Physiol. 47, 141-153. doi: $10.1093 / \mathrm{pcp} / \mathrm{pci} 230$

James, C. (2013). "Global status of commercialized biotech/GM crops: 2013," in International Service for the Acquisition of Agri-biotech Applications. Brief No. 46 (Ithaca, NY: ISAAA).

Jan, A., Maruyama, K., Todaka, D., Kidokorom, S., Abo, M., Yoshimura, E., et al. (2013). OsTZF1, a $\mathrm{CCCH}$-tandem zinc finger protein, confers delayed senescence and stress tolerance in rice by regulating stress-related genes. Plant Physiol. 161, 1202-1216. doi: 10.1104/pp.112.205385

Jeong, J. S., Kim, Y. S., Baek, K. H., Jung, H., Ha, S.-H., Choi, Y. D., et al. (2010). Root-specific expression of OsNAC10 improves drought tolerance and grain 
yield in rice under field drought conditions. Plant Physiol. 153, 185-197. doi: 10.1104/pp.110.154773

Kalamaki, M. S., Merkouropoulos, G., and Kanellis, A. K. (2009). Can ornithine accumulation modulate abiotic stress tolerance in Arabidopsis? Plant Signal. Behav. 4, 1099-1101. doi: 10.4161/psb.4. 11.9873

Kasukabe, Y., He, L., Watakabe, Y., Otani, M., Shimada, T., and Tachibana, S. (2006). Improvement of environmental stress tolerance of sweet potato by introduction of genes for spermidine synthase. Plant Biotechnol. 23, 75-83. doi: 10.5511/plantbiotechnology.23.75

Kazuko, Y. S., and Shinozaki, K. (2006). Transcriptional regulatory networks in cellular responses and tolerance to dehydration and cold stresses. Annu. Rev. Plant Biol. 57, 781-803. doi: 10.1146/annurev.arplant.57.032905.105444

Köhler, B., and Mueller-Roeber, B. (2004). Remote control - cell and organ communication within plants. New Phytol. 161, 321-324. doi: 10.1111/j.1469-8137.2004.00988.x

Kusano, T., Berberich, T., Tateda, C., and Takahashi, Y. (2008). Polyamines: essential factors for growth and survival. Planta 228, 367-381. doi: 10.1007/s00425-008-0772-7

Lee, J., and Scagel, C. F. (2014). Chicoric acid: chemistry, distribution, and production. Front. Chem. 1:40. doi: 10.3389/fchem.2013.00040

Lindenmayer, D. B., Likens, G. E., Krebs, C. J., and Hobbs, R. J. (2010) Improved probability of detection of ecological "surprises." Proc. Natl. Acad. Sci. U.S.A. 107, 21957-21962. doi: 10.1073/pnas.1015696107

Lipiec, J., Doussan, C., Nosalewicz, A., and Kondracka, K. (2013). Effect of drought and heat stresses on plant growth and yield: a review. Int. Agrophys. 27, 463-477. doi: 10.2478/intag-2013-0017

Liu, C., Wu, Y., and Wang, X. (2012). bZIP transcription factor OsbZIP52/RISBZ5: a potential negative regulator of cold and drought stress response in rice. Planta 235, 1157-1169. doi: 10.1007/s00425011-1564-z

Liu, J. H., Kitashiba, H., Wang, J., Ban, Y., and Moriguchi, T. (2007). Polyamines and their ability to provide environmental stress tolerance to plants. Plant Biotechnol. 24, 117-122. doi: 10.5511/plantbiotechnology.24.117

Liu, X., Chen, M., Collins, H. L., Onstad, D. W., Roush, R. T., et al. (2014). Natural enemies delay insect resistance to Bt crops. PLoS ONE 9:e90366. doi: 10.1371/journal.pone.0090366

Lu, G., Gao, C., Zheng, X., and Han, B. (2009). Identification of OsbZIP72 as a positive regulator of ABA response and drought tolerance in rice. Planta 229, 605-615. doi: 10.1007/s00425008-0857-3

Luo, M., Liu, X., Singh, P., Cui, Y., Zimmerli, L., and $\mathrm{Wu}, \mathrm{K}$. (2012). Chromatin modifications and remodeling in plant abiotic stress responses. Biochim. Biophys. Acta 1819, 129-136. doi: 10.1016/j.bbagrm.2011.06.008

Marvier, M., McCreedy, C., Regetz, J., and Kareiva, P. (2007). A meta-analysis of effects of Bt cotton and maize on nontarget invertebrates. Science 316, 1475-1477. doi: 10.1126/science. 1139208

Mattoo, A. K. (2013). "Agricultural biology in the 3rd millennium: Nutritional food security and specialty crops through sustainable agriculture and biotechnology," in Diamond Jubilee Commemoration Volume: Research and Development from the Past Decade, eds D. V. Amla, P. Nath, D. K. Uprati, N. Singh, and K. M. Nair (Lucknow: Army Printing Press), 9-14.

Mattoo, A. K., Chung, S.-H., Goyal, R. K., Fatima, T., Srivastava, A., Solomos, T., et al. (2007). Overaccumulation of higher polyamines in ripening transgenic tomato fruit revives metabolic memory, upregulates anabolism-related genes, and positively impacts nutritional quality. J. AOAC Intl. 90 , 1456-1464.

Mattoo, A. K., and Handa, A. K. (2008). Higher polyamines resuscitate metabolic memory in fruit. Plant Sci. 174, 386-393. doi: 10.1016/j.plantsci.2008.01.011

Mattoo, A. K., Shukla, V., Fatima, T., Handa, A. K., and Yachha, S. K. (2010). "Genetic engineering to enhance crop-based phytonutrients (nutraceuticals) to alleviate diet-related diseases," in BioFarms for Nutraceuticals: Functional Food and Safety Control by Biosensors, eds M. T. Giardi, G. Rea, and B. Berra (New York, NY: Landes Bioscience and Springer), 122-143.

Mattoo, A. K., Sobolev, A. P., Neelam, A., Goyal, R. K., Handa, A. K., and Segre, A. L. (2006). NMR spectroscopy-based metabolite profiling of transgenic tomato fruit engineered to accumulate spermidine and spermine reveals enhanced anabolic and nitrogen-carbon interactions. Plant Physiol. 142, 1759-1770. doi: 10.1104/pp.106.084400

Mattoo, A. K., and Teasdale, J. R. (2010). Ecological and genetic systems underlying sustainable horticulture. Hort. Revs. 37, 331-362.

Mattoo, A. K., Upadhyay, R. K., and Rudrabhatla, S. (2014). "Abiotic stress in crops: candidate genes, osmolytes, polyamines and biotechnological intervention," in Elucidation of Abiotic Stress Signaling in Plants: a Functional Genomic Perspective, ed G. K. Pandey (New York, NY: Springer). (in press).

Mehta, R. A., Cassol, T., Li, N., Ali, N., Handa, A. K., and Mattoo, A. K. (2002). Engineered polyamine accumulation in tomato enhances phytonutrient content, juice quality and vine life. Nat. Biotechnol. 20, 613-618. doi: 10.1038/nbt0602-613

Meyer, K. M., Soldaat, L. I., Auge, H., and Thulke, H.-H. (2014). Adaptive and selective seed abortion reveals complex conditional decision making in plants. Am. Nat. 183, 376-383. doi: $10.1086 / 675063$

Mittler, R. (2006). Abiotic stress, the field environment and stress combination. Trends Plant Sci. 11, 15-19. doi: 10.1016/j.tplants.2005.11.002

$\mathrm{Mu}, \mathrm{C}$, Zhang, S., Yu, G., Chen, N., and Li, X. (2013). Overexpression of small heat shock protein LimHSP16.45 in Arabidopsis enhances tolerance to abiotic stresses. PLOS ONE 8:e82264. doi: 10.1371/journal.pone.0082264

Muir, S. R., Collins, G. J., Robinson, S., Hughes, S., Bovy, A., Rich De Vos, C. H., et al. (2001). Overexpression of petunia chalcone isomerase in tomato results in fruit containing increased levels of flavonols. Nat. Biotechnol. 19, 470-474. doi: $10.1038 / 88150$

Nakashima, K., Tran, L. S., van Nguyen, D., Fujita, M., Maruyama, K., Todaka, D., et al. (2007). Functional analysis of a NAC-type transcription factor OsNAC6 involved in abiotic and biotic stress responsive gene expression in rice. Plant J. 51, 617-630. doi: 10.1111/j.1365-313X.2007. 03168.x

Nambessan, S., Datsenka, T., Ferruzzi, M. G., Malladi, A., Mattoo, A. K., and Handa, A. K. (2010). Overexpression of yeast spermidine synthase impacts ripening, senescence and decay symptoms in tomato. Plant J. 63, 836-847. doi: 10.1111/j.1365-313X.2010.04286.x

Naqvi, S., Zhu, C., Farre, G., Ramessar, K., Bassie, L., Breitenbach, J., et al. (2009). Transgenic multivitamin corn through biofortification of endosperm with three vitamins representing three distinct metabolic pathways. Proc. Natl. Acad. Sci. U.S.A. 106, 7762-7767. doi: 10.1073/pnas.0901 412106

Navakouidis, E., Lütz, C., Langebartels, C., LützMeindl, U., and Kotzabasis, K. (2003). Ozone impact on the photosynthetic apparatus and the protective role of polyamines. Biochem. Biophys. Acta 1621, 160-169. doi: 10.1016/S03044165(03)00056-4

Neelam, A., Cassol, T., Mehta, R. A., Abdul-Baki, A. A., Sobolev, A., Goyal, R. K., et al. (2008). A fieldgrown transgenic tomato line expressing higher levels of polyamines reveals legume cover crop mulch-specific perturbations in fruit phenotype at the levels of metabolite profiles, gene expression and agronomic characteristics. J. Exp. Bot. 59, 2337-2346. doi: 10.1093/jxb/ern100

Nelissen, H., Moloney, M., and Inz, D. (2014) Translational research: from pot to plot. Plant Biotechnol. J. 12, 277-285. doi: 10.1111/pbi.12176

Nelson, D. E., Repetti, P. P., Adams, T. R., Creelman, R. A., Wu, J., Warner, D. C., et al. (2007). Plant nuclear factor Y (NF-Y) B subunits confer drought tolerance and lead to improved corn yields on water-limited acres. Proc. Natl. Acad. Sci. U.S.A. 104, 16450-16455. doi: 10.1073/pnas.0707 193104

Niggeweg, R., Michael, A. J., and Martin, C. (2004). Engineering plants with increased levels of the antioxidant chlorogenic acid. Nat. Biotechnol. 22, 746-754. doi: 10.1038/nbt966

Ning, J., Li, X., Hicks, L. M., and Xiong, L. (2010). A Raf-like MAPKKK gene DSM1 mediates drought resistance through reactive oxygen species scavenging in rice. Plant Physiol. 152, 876-890. doi: 10.1104/pp.109.149856

Oh, S. J., Kim, Y. S., Kwon, C. W., Park, H. K., Jeong, J. S., and Kim, J. K. (2009). Overexpression of the transcription factor AP37 in rice improves grain yield under drought conditions. Plant Physiol. 250, 1368-1379. doi: 10.1104/pp.109.137554

Ort, D. R., and Yocum, C. F. (eds). (1996). Oxygenic Photosynthesis: The Light Reactions. Advances in Photosynthesis, Vol. 4. Dordrecht: Kluwer Academic Publishers.

Paine, J. A., Shipton, C. A., Chaggar, S., Howells, R. M., Kennedy, M. J., Vernon, G., et al. (2005). Improving the nutritional value of golden rice through increased pro-vitamin A content. Nat. Biotechnol. 23, 482-487. doi: 10.1038/nbt1082

Petrusa, L. M., and Winicov, I. (1997). Proline status in salt tolerant and salt sensitive alfalfa cell lines and plants in response to $\mathrm{NaCl}$. Plant Physiol. Biochem. 35, 303-310.

Porter, J. R., and Semenov, M. A. (2005). Crop responses to climatic variation. Philos. Trans. 
R. Soc. B Biol. Sci. 360, 2021-2035. doi: 10.1098/rstb.2005.1752

Quan, R., Hu, S., Zhang, Z., Zhang, H., Zhang, Z., and Huang, R. (2010). Overexpression of an ERF transcription factor TSRF1 improves rice drought tolerance. Plant Biotechnol. J. 8, 476-488. doi: 10.1111/j.1467-7652.2009.00492.x

Quan, R., Shang, M., Zhang, H., Zhao, Y., and Zhang, J. (2004). Engineering of enhanced glycinebetaine synthesis improves drought tolerance in maize. Plant Biotechnol. J. 2, 477-486. doi: 10.1111/j.1467-7652.2004.00093.x

Reugera, M., Peleg, Z., and Blumwald, M. (2012). Targeting metabolic pathways for genetic engineering abiotic stress-tolerance in crops. Biochim. Biophys. Acta 1819, 186-194. doi: 10.1016/j.bbagrm.2011.08.005

Riechmann, J. L., and Ratcliffe, O. J. (2000). A genomic perspective on plant transcription factors. Curr. Opin. Plant. Biol. 3, 423-434. doi: 10.1016/S1369-5266(00)00107-2

Römer, S., Fraser, P. D., Kiano, J. W., Shipton, C. A., Misawa, N., Schuch, W., et al. (2000) Eevation of the provitamin A content of transgenic tomato plants. Nat. Biotechnol. 18, 666-669. doi: $10.1038 / 76523$

Ronald, P. (2011). Plant genetics, sustainable agriculture and global food security. Genetics 188, 11-20. doi: 10.1534/genetics.111.128553

Rosati, C., Aquilani, R., Dharmapuri, S., Pallara, P., Marusic, C., Tavazza, R., et al. (2000). Metabolic engineering of beta carotene and lycopene content in tomato fruit. Plant J. 24, 413-419. doi: 10.1046/j.1365-313x.2000.00880.x

Roy, M., and Wu, R. (2002). Overexpression of $S$-adenosylmethionine decarboxylase gene in rice increases polyamine level and enhances sodium chloride-stress tolerance. Plant Sci. 163, 987-992. doi: 10.1016/S0168-9452(02)00272-8

Ruiz-Medrano, R., Xoconostle-Cazares, B., and Lucas, W. J. (2001). The phloem as a conduit for inter-organ communication. Curr. Opin. Plant Biol. 4, 202-209. doi: 10.1016/S1369-5266(00) 00162-X

Saijo, Y., Hata, S., Kyozuka, J., Shimamoto, K., and Izui, K. (2000). Over-expression of a single $\mathrm{Ca}^{2+}$-dependednt protein kinase confers both cold and salt/drought tolerance on rice plants. Plant J. 23, 319-327. doi: 10.1046/j.1365-313x.2000. 00787.x

Saito, K., and Matsuda, F. (2010). Metabolomics for functional genomics, systems biology, and biotechnology. Annu. Rev. Plant Biol. 61, 463-489. doi: 10.1146/annurev.arplant.043008.092035

Sakamoto, A., and Murata, N. (2002) The role of glycine betaine in the protection of plants from stress: clues from transgenic plants. Plant Cell Environ. 25, 163-171. doi: 10.1046/j.00168025.2001.00790.x

Saradhi, P. P., Suzuki, I., Katoh, A., Sakamoto, A., Sharmilla, P., Shi, D. J., et al. (2000). Protection against the photo-induced inactivation of the photosystem II complex by abscisic acid. Plant Cell Environ. 23, 711-718. doi: 10.1046/j.13653040.2000.00579.x

Schijlen, E., Ric de Vos, C. H., Jonker, H., van den Broeck, H., Molthoff, J., van Tunen, A., et al. (2006). Pathway engineering for healthy phytochemicals leading to the production of novel flavonoids in tomato fruit. Plant Biotechnol. J. 4, 433-444. doi: 10.1111/j.1467-7652.2006 00192.x

Schmitz, R. J., and Zhang, X. (2011). Highthroughput approaches for plant epigenomic studies. Curr. Opin. Plant Biol. 14, 130-136. doi: 10.1016/j.pbi.2011.03.010

Sengupta, S., Patra, B., Ray, S., and Majumder, A. L. (2008). Inositol methyl transferase from a halophytic wild rice, Porteresia coarctata Roxb. (Tateoka): regulation of pinitol synthesis under abiotic stress. Plant Cell Environ. 31, 1442-1459. doi: 10.1111/j.1365-3040.2008. 01850.x

Shou, H., Bordallo, P., Fan, J. B., Bibikova, J. M. Sheen, J., and Wang, K. (2004). Expression of an active tobacco mitogen-activated protein kinase kinase kinase enhances freezing tolerance in transgenic maize. Proc. Natl. Acad. Sci. U.S.A. 101 3298-3303. doi: 10.1073/pnas.0308095100

Shukla, V., and Mattoo, A. K. (2010). Potential for engineering horticultural crops with high antioxidant capacity. CAB Reviews 4, 1-22. doi: 10.1079/ PAVSNNR20094066

Shukla, V., and Mattoo, A. K. (2013). "Developing robust crop plants for sustaining growth and yield under adverse climatic changes," in Climate Change and Plant Abiotic Stress Tolerance, eds N. Tuteja and S. Gill (Germany: Wiley-VCH Verlag), 27-56.

Sobolev, A. P., Capitani, D., Giannino, D., Nicolodi, C., Testone, G., Santoro, F., et al. (2010). NMR metabolic methodology in the study of GM foods. Nutrients 2, 1-15. doi: 10.3390/nu2010001

Su, C.-F., Wang, Y.-C., Hsieh, T.-H., Lu, C.-H., Tseng, T.-H., and Yu, S.-M. (2010). A novel MYBS3-dependent pathway confers cold tolerance in rice. Plant Physiol. 153, 145-158. doi: 10.1104/pp.110.153015

Sun, L., Yuan, B., Zhang, M., Wang, L., Cui, M., Wang, Q., et al. (2012). Fruit-specific RNAimediated suppression of SINCED1 increases both lycopene and $\beta$-carotene contents in tomato fruit. J. Exp. Bot. 63, 3097-3108. doi: 10.1093/jxb/ ers026

Takasaki, H., Maruyama, K., Kidokoro, S., Ito, Y., Fujita, Y., Shinozaki, K., et al. (2010). The abiotic stress responsive $N A C$-type transcription factor OsNAC5 regulates stress-inducible genes and stress tolerance in rice. Mol. Genet. Genom. 84, 173-183. doi: 10.1007/s00438-010-0557-0

Vierling, E. (1991). The roles of heat shock proteins in plants. Annu. Rev. Plant Physiol. Plant Mol. Biol. 42, 579-620. doi: 10.1146/annurev.pp.42.060191.003051

Vincour, B., and Altman, A. (2005). Recent advances in engineering plant tolerance to abiotic stress: achievements and limitations. Curr. Opin. Biotechnol. 16, 123-132. doi: 10.1016/j.copbio.2005.02.001

Wan, L., Zhang, J., Zhang, H., Zhang, Z., Quan, R., Zhou, S., et al. (2011). Transcriptional activation of OsDERF1 in OsERF3 and OsAP239 negatively modulates ethylene synthesis and drought tolerance in rice. PLOS ONE 6:e25216. doi: 10.1371/journal.pone.0025216

Wang, G. P., Zhang, X. Y., Li, F., Luo, Y., and Wang, W. (2010). Over accumulation of glycinebetaine enhances tolerance to drought and heat stress in wheat leaves in the protection of photosynthesis Photosynthetica 48, 117-126. doi: 10.1007/s11099010-0016-5

Wang, W., Vincour, B., Shoseyov, O., and Altman, A. (2004). Role of plant heat-shock proteins and molecular chaperones in the abiotic stress response. Trends Plant Sci. 9, 244-252. doi: 10.1016/j.tplants.2004.03.006

Weiste, C., Iven, T., Fischer, U., Oñate-Sánchez, L., and Dröge-Laser, W. (2007). In planta ORFeome analysis by large-scale over-expression of GATEWAYcompatible cDNA clones: screening of ERF transcription factors involved in abiotic stress defense. Plant J. 52, 382-390. doi: 10.1111/j.1365313X.2007.03229.

Wen, X. P., Pang, X. M., Matsuda, N., Kita, M., Inoue, M., Hao, Y. J., et al. (2008). Overexpression of the apple spermidine synthase gene in pear confers multiple abiotic stress tolerance by altering polyamine titers. Transgenic Res. 17, 251-263. doi: 10.1007/s11248-007-9098-7

Wi, S. J., Kim, W. T., and Park, K. Y. (2006). Over expression of carnation S-adenosylmethionine decarboxylase gene generates a broad-spectrum tolerance to abiotic stresses in transgenic tobacco plants. Plant Cell Rep. 25, 1111-1121. doi 10.1007/s00299-006-0160-3

Wingler, A. (2002). The function of trehalose biosynthesis in plants. Phytochemistry 60, 437-440. doi: 10.1016/S0031-9422(02)00137-1

Wise, R. R., and Hoober, J. K. (2007). The Structure and Function of Plastids. Advances in Photosynthesis and Respiration, Vol. 23. New York, NY: Springer.

Wu, X., Shiroto, Y., Kishitani, S., Ito, Y., and Toriyama, K. (2008). Enhanced heat and drought tolerance in transgenic rice seedlings overexpressing OsWRKY11 under the control of HSP101 promoter. Plant Cell Rep. 28, 21-30. doi: 10.1007/s00299-008-0614-X

Xiang, Y., Tang, N., Du, H., Ye, H., and Xiong, L. (2008). Characterization of OsbZIP23 as a key player of the basic leucine zipper transcription factor family for conferring abscisic acid sensitivity and salinity and drought tolerance in rice. Plant Physiol. 148, 1938-1952. doi: 10.1104/pp.108.128199

Xiao, B., Huang, Y., Tang, N., and Xiong, L. (2007) Over-expression of a LEA gene in rice improves drought resistance under the field conditions. Theor. Appl. Genet. 115, 35-46. doi: 10.1007/s00122-007-0538-9

Xiong, A. S., Jiang, H. H., Zhuang, J., Peng, R. H., Jin, X. F., Zhu, B., et al. (2013). Expression and function of a modified AP2/ERF transcription factor from Brassica napus enhances cold tolerance in transgenic Arabidopsis. Mol. Biotechnol. 53 198-206. doi: 10.1007/s12033-012-9515-x

Xiong, L., Lee, B. L., Ishitani, M., Lee, H., Zhang, C., and Zhu, J.-K. (2001). FIERY1 encoding an inositol polyphosphate 1-phosphatase is a negative regulator of abscisic acid and stress signaling in Arabidopsis. Genes Dev. 15, 1971-1984. doi: 10.1101/gad.891901

Xu, D., Duan, X., Wang, B., Hong, B., Ho, T. H. D., and $\mathrm{Wu}, \mathrm{R}$. (1996). Expression of a late embryogenesis abundant protein gene $H V A 1$, from barley confers tolerance to water deficit and salt stress in transgenic rice. Plant Physiol. 110, 249-257. 
Yang, A., Dai, X., and Zhang, W.-H. (2012). A R2R3typre MYB gene, OsMYB2, is involved in salt, cold, and dehydration tolerance in rice. J. Exp. Bot. 63, 2541-2556. doi: 10.1093/jxb/err431

Yanhui, C., Xiaoyuan, Y., Kun, H., Meihua, L., Jigang, L., Zhaofeng, G., et al. (2012). A R2R3-typre MYB gene, OsMYB2, is involved in salt, cold, and dehydration tolerance in rice. J. Exp. Bot. 63, 2541-2556. doi: 10.1093/jxb/err431

Zhang, H., Liu, W., Wan, L., Li, F., Dai, L., Li, D., et al. (2010). Functional analyses of ethylene response factor JERF3 with the aim of improving tolerance to drought and osmotic stress in transgenic rice. Transgenic Res. 19, 809-818. doi: 10.1007/s11248009-9357-x

Zhang, W., Lorence, A., Gruszewski, H. A., Chevone, B. I., and Nessler, C. L. (2009). AMR1, an Arabidopsis gene that coordinately and negatively regulates the mannose/l-galactose ascorbic acid biosynthetic pathway. Plant Physiol. 150, 942-950. doi: 10.1104/pp.109.138453

Zhao, L., Hu, Y., Chong, K., and Wang, T. (2010). ARAG1, an ABA-responsive DREB gene, plays a role in seed germination and drought tolerance of rice. Ann. Bot. 105, 401-409. doi: 10.1093/aob/mcp303

Zou, M., Guan, Y., Ren, H., Zhang, F., and Chen, F. (2008). A bZIP transcription factor, OsABI5 is involved in rice fertility and stress tolerance. Plant Mol. Biol. 66, 675-683. doi: 10.1007/s11103-0089298-4

Conflict of Interest Statement: The authors declare that the research was conducted in the absence of any commercial or financial relationships that could be construed as a potential conflict of interest.
Received: 11 April 2014; accepted: 05 May 2014; published online: 05 June 2014.

Citation: Mattoo AK (2014) Translational research in agricultural biology —enhancing crop resistivity against environmental stress alongside nutritional quality. Front. Chem. 2:30. doi: 10.3389/fchem.2014.00030

This article was submitted to Agricultural Biological Chemistry, a section of the journal Frontiers in Chemistry.

Copyright () 2014 Mattoo. This is an open-access article distributed under the terms of the Creative Commons Attribution License (CC BY). The use, distribution or reproduction in other forums is permitted, provided the original author(s) or licensor are credited and that the original publication in this journal is cited, in accordance with accepted academic practice. No use, distribution or reproduction is permitted which does not comply with these terms. 